\title{
Anesthesia for cesarean section in parturients diagnosed with placenta previa in a Thai university hospital: a retrospective analysis of 562 consecutive cases
}

\author{
Pornarun Charoenraj ${ }^{\mathrm{a}}$, Somrat Charuluxananan ${ }^{\mathrm{a}}$, Phornlert Chatrkaw ${ }^{\mathrm{a}}$, Chooksak Tunprasit \\ Parinya Wangdumrongwong ${ }^{\mathrm{b}}$, Vorapong Phupong ${ }^{\mathrm{c}}$ \\ ${ }^{a}$ Department of Anesthesiology, Faculty of Medicine, Chulalongkorn University, ${ }^{b}$ Department of \\ Anesthesiology, King Chulalongkorn Memorial Hospital, Thai Red Cross Society, ${ }^{c}$ Department of \\ Obstetrics and Gynecology, Faculty of Medicine, Chulalongkorn University, Bangkok 10330, Thailand
}

\begin{abstract}
Background: Anesthesia for cesarean delivery in parturients diagnosed with placenta previa remains controversial. Objectives: To investigate factors correlated with choice of anesthesia in these parturients and their outcomes. Methods: Retrospective analysis of patients with placenta previa and cesarean delivery at King Chulalongkorn Memorial Hospital. Peri operative anesthetic and complication data were collected using a structured collection form. Univariate analysis and multivariate logistic regression were used. $P<0.05$ was considered significant. Results: Among 50,237 deliveries from July 1, 2005 to June 30, 2011, there were 562 cesarean sections in diagnosed cases of placenta previa. Cesarean deliveries (479) were performed under spinal anesthesia (81\%), epidural anesthesia (1.8\%), and if the effects spinal anesthesia dissipated, general anesthesia (2.3\%). Among 46 cases of cesarean hysterectomy, 27 patients (58.7\%) received regional anesthesia. However, 6 of 10 patients with planned cesarean hysterectomy underwent general anesthesia, while 1 of 4 of a group with regional anesthesia needed conversion to general anesthesia. There was no serious anesthesia-related complication. Factors related to general anesthesia were: a higher American Society of Anesthesiologists (ASA) physical status OR 2.7 (95\% CI 1.7-4.3) $P<0.001$; presentation with bleeding OR 1.8(95\% CI 1.0-3.1) $P=0.033$; anterior site of placenta OR 1.8 (95\% CI 1.1-3.2) $P=0.025$; heart rate $>125$ bpm OR 5.6 (95\% CI 1.5-214) $P=0.01$; and pack red cell transfusion OR 3.4 (95\% CI 2.0-5.7) $P<0.001$.
\end{abstract}

Conclusions: Most parturients received regional anesthesia. Neuroaxial anesthesia and general anesthesia are safe.

Keywords: Cesarean delivery, choice of anesthesia, complication, neuraxial anesthesia, placenta previa, spinal anesthesia

Placenta previa, is a major cause of massive hemorrhage and can result in maternal or fetal morbidity and mortality [1, 2]. Its incidence is 4.8 per 1000 deliveries with a mortality rate of $0.03 \%$ [3]. The best anesthesia for cesarean delivery remains controversial. General anesthesia is believed to be preferable for this group of patients [4]. There is also evidence that a majority of anesthesiologists consider using regional anesthesia for placenta previa [4-6].

Obstetric complications have recently been highlighted by the mass media in Thailand. This situation dramatically increased as referral of high

Correspondence to: Somrat Charuluxananan, Department of Anesthesiology, Faculty of Medicine, Chulalongkorn University, Bangkok 10330, Thailand. E-mail: somratcu@hotmail.com risk obstetric patients for medical services to tertiary care hospitals increased. Our institution developed guidelines for anesthesia for placenta previa, but technique was left to the discretion of the individual anesthesiologist. We performed a retrospective analysis of cases to investigate factors correlating with choice of anesthesia for cesarean delivery.

\section{Methods}

This study was approved by our institutional ethics committee and written informed consent was waived (IRB No.298/52). We investigated demographic, obstetric, and anesthetic data of all parturients with placenta previa (including placental adherence such as placenta increta, accreta, and percreta) who received anesthesia for cesarean delivery in a 
retrospective-cohort fashion (between July 1, 2005 and December 31, 2009 and prospectively between Jan 1, 2010 and June 30, 2011). The study was conducted at King Chulalongkorn Memorial Hospital, Bangkok, a 1500-bed tertiary-referral university teaching hospital. We extracted data from the hospital's computerized database, hand-written labor ward register, and the obstetric operating theatre register using a structured case-record form.

For each patient, the following information was recorded: gestation, previous cesarean delivery, type of placenta previa, position of placenta (from ultrasound reports or description at surgery), emergency or elective (as defined by the obstetrician), clinical presentation, preoperative vital signs, preoperative hematocrit, estimated blood loss during surgery, intraoperative and postoperative (within 24 h) blood transfusions, intraoperative administration of ephedrine or methylergometrine (Methergine), postoperative hematocrit, duration of anesthesia, admission to intensive care unit, length of hospital stay, and main anesthetic techniques for cesarean delivery. Main anesthetic techniques were classified into 2 groups: I: a general anesthesia (GA) group including general anesthesia and general anesthesia after failed or inadequate spinal anesthesia. II: A regional anesthesia (RA) group including spinal anesthesia, epidural anesthesia, and general anesthesia after the effects of spinal anesthetic had dissipated.

Data were analyzed using SPSS for Windows version 17 . Factors potentially associated with choice of anesthesia were assessed by using a $t$ test (for continuous data) and Chi-square test or Fisher's exact test (for categorical data). Multivariate logistic regression with a forward stepwise approach was then used to identify the magnitude of association in term of crude odds ratio with a $95 \%$ confidence interval (95\% CI). In all cases, two-tailed tests were performed, and $P<0.05$ was considered statistically significant.

\section{Results}

During the 6-year study period, there were 50,237 deliveries in our institution and 562 (1.1\%) consecutive parturients with a diagnosis of placenta previa who underwent cesarean delivery. Seventy (12.4\%) parturients received general anesthesia, and 14 (2.5\%) parturients received general anesthesia after failure or inadequate spinal blockade and were classified in the general anesthesia (GA) group. In the regional anesthesia (RA) group, there were 455 (81.0\%) parturients who received spinal anesthesia, 10 (1.8\%) parturients who received epidural anesthesia, and 13 (2.3\%) parturients who received spinal anesthesia throughout with subsequent induction of general anesthesia. Three hundred eighty-nine of 471 (82.6\%) parturients received regional anesthesia and were categorized in the RA group during the retrospective data collection period (July 1, 2003 to December 31, 2008), whereas 80 of 91 (87.9\%) parturients received regional anesthesia during the prospective data collection period (January 1, 2009 to June 30, 2010), and the rates were not statistically significantly different $(P=0.273)$.

In the database, there were 46 cases $(8.2 \%)$ of hysterectomy and 29 cases (5.2\%) of abnormal placentation (placenta accreta, placenta percreta, or placenta increta). Twenty-seven patients undergoing hysterectomy (58.7\% of 46 cases) and were in the RA group. However, there were 10 patients with planned cesarean hysterectomy, while 6 patients (60\%) received general anesthesia. Among these, 4 of 10 were associated with preoperative diagnosis of placental adherence and 6 of 10 cases were associated with frank antenatal bleeding. Details of choices of anesthesia among the subgroup of patients with hysterectomy and/or placental adherence are shown in Table 1.

The demographic data of parturients in the GA and RA groups were comparable except for body weight $(P=0.03)$. The proportion of patients who underwent emergency cesarean section in the GA group (78.6\%) was higher than that in the RA group (61.7\%); $P=0.004$. Univariate analysis of the preanesthetic characteristics of the patients are shown in Table 2. Types of placenta previa $(P<0.001)$, placental site or location $(P=0.002)$, and placental adherence $(P=0.012)$ were significantly different factors between the GA and RA groups in the univariate analysis. Duration of anesthesia of patients in the GA and the RA groups were $77.9 \pm 47.9 \mathrm{~min}$ and $60.4 \pm 26.8$ min respectively $(P=0.002)$. The estimated blood loss in patients from the G.A. group was $1610.7 \pm 1684.4 \mathrm{~mL}$, which was higher than average of the R.A. group of $1161.2 \pm 1104.2 \mathrm{~mL}$ $(P=0.002)$. Fourteen patients (16.7\%) in the GA group required administration of ephedrine compared with 317 (66.3\%) patients in the RA group; $(P=0.001)$. The proportion of patients receiving packed red cell, fresh frozen plasma, or platelet transfusion was 
significantly higher in the GA group than in the RA group. The proportion of Apgar score was $<7$ at $1 \mathrm{~min}$, at $5 \mathrm{~min}$, the proportion of patients with a postoperative hematocrit $<30 \%$ of the GA group was also significantly higher than in the RA group. Details of the intraoperative and postoperative characteristics between the 2 groups are shown in Table 3 .

Table 1. Anesthetic techniques used for patients with placenta previa undergoing cesarean delivery

\begin{tabular}{|c|c|c|c|c|c|c|}
\hline & \multicolumn{2}{|r|}{ GA Group } & \multicolumn{3}{|c|}{ RA Group } & \multirow[b]{2}{*}{ Total } \\
\hline & GA & GA because of failed SA & SA & SA dissipated & Epidural & \\
\hline \multirow[t]{2}{*}{ Placenta previa } & 70 & 14 & 455 & 13 & 10 & 562 \\
\hline & $(12.4 \%)$ & $(2.5 \%)$ & $(81.0 \%)$ & $(2.3 \%)$ & $(1.8 \%)$ & $(100 \%)$ \\
\hline \multirow[t]{2}{*}{ Hysterectomy } & 18 & 1 & 15 & 11 & 1 & 46 \\
\hline & (39.1\%) & $(2.2 \%)$ & (32.6\%) & $(23.9 \%)$ & $(2.2 \%)$ & $(100 \%)$ \\
\hline \multirow{2}{*}{$\begin{array}{l}\text { Planned Cesarean } \\
\text { hysterectomy }\end{array}$} & 6 & 0 & 3 & 1 & 0 & 10 \\
\hline & $(60 \%)$ & $(0 \%)$ & $(30 \%)$ & $(10 \%)$ & $(0 \%)$ & $(100 \%)$ \\
\hline \multirow{2}{*}{$\begin{array}{l}\text { Unplanned Cesarean } \\
\text { hysterectomy }\end{array}$} & 12 & 1 & 12 & 10 & 1 & 36 \\
\hline & (33.3\%) & $(2.8 \%)$ & (33.3\%) & $(27.7 \%)$ & $(2.8 \%)$ & $(100 \%)$ \\
\hline \multirow[t]{2}{*}{ Placental adherence } & 8 & 1 & 12 & 8 & 0 & 29 \\
\hline & $(27.6 \%)$ & $(3.4 \%)$ & (41.4\%) & $(27.6 \%)$ & $(0 \%)$ & $(100 \%)$ \\
\hline \multirow{2}{*}{$\begin{array}{l}\text { Placental adherence with } \\
\text { hysterectomy }\end{array}$} & 6 & 1 & 5 & 8 & 0 & 20 \\
\hline & (30.0\%) & $(5.0 \%)$ & (25.0\%) & $(40.0 \%)$ & $(0 \%)$ & (100\%) \\
\hline \multirow{2}{*}{$\begin{array}{l}\text { Placental adherence without } \\
\text { hysterectomy }\end{array}$} & 2 & 0 & 7 & 0 & 0 & 9 \\
\hline & (22.2\%) & $(0 \%)$ & (77.8\%) & $(0 \%)$ & (0\%) & $(100 \%)$ \\
\hline
\end{tabular}

$\mathrm{GA}=$ general anesthesia, $\mathrm{RA}=$ regional anesthesia, $\mathrm{SA}=$ spinal anesthesia

Table 2. Univariate analysis of demographic and preanesthetic characteristics $(n=562)$

\begin{tabular}{|c|c|c|c|c|c|}
\hline & \multicolumn{2}{|c|}{ General anesthesia } & \multicolumn{2}{|c|}{ Regional anesthesia } & \multirow[b]{2}{*}{$\mathbf{P}$} \\
\hline & $\mathbf{n}$ & $\%$ & $\mathbf{n}$ & $\%$ & \\
\hline Age (y) & 84 & $33.1 \pm 4.6$ & 478 & $32.7 \pm 4.8$ & 0.52 \\
\hline Weight (kg) & 84 & $63.5 \pm 10.4$ & 478 & $65.9 \pm 9.3$ & 0.03 \\
\hline Height $(\mathrm{cm})$ & 84 & $157.4 \pm 5.6$ & 478 & $157.3 \pm 5.4$ & 0.99 \\
\hline Gestational age (wk) & 84 & $33.4 \pm 4.6$ & 478 & $36.5 \pm 2.6$ & $<0.001$ \\
\hline Preanesthetic systolic pressure (mmHg) & 84 & $126.1 \pm 17.5$ & 478 & $121.8 \pm 14.4$ & 0.036 \\
\hline ASA physical status & & & & & $<0.001$ \\
\hline 1 & 50 & $59.5 \%$ & 401 & $83.9 \%$ & \\
\hline 2 & 26 & $31.0 \%$ & 75 & $15.7 \%$ & \\
\hline 3 & 7 & $8.3 \%$ & 2 & $4 \%$ & \\
\hline 4 & 1 & $1.2 \%$ & 0 & $0 \%$ & \\
\hline Surgical status & & & & & 0.004 \\
\hline Emergency & 66 & $78.6 \%$ & 296 & $61.7 \%$ & \\
\hline Elective & 18 & $21.4 \%$ & 183 & $38.3 \%$ & \\
\hline Presentation & & & & & 0.008 \\
\hline Bleeding & 52 & $61.9 \%$ & 205 & $42.9 \%$ & \\
\hline Labor pain & 4 & $4.8 \%$ & 48 & $10 \%$ & \\
\hline Contraction & 3 & $3.6 \%$ & 13 & $2.7 \%$ & \\
\hline No symptom & 17 & $20.2 \%$ & 177 & $37 \%$ & \\
\hline Bleeding + contraction & 3 & $2.6 \%$ & 4 & $0.8 \%$ & \\
\hline Labor pain + contraction & 1 & $3.6 \%$ & 4 & $0.8 \%$ & \\
\hline Bleeding + labor pain + contraction & 1 & $1.2 \%$ & 1 & $0.2 \%$ & \\
\hline Previous C/S & 24 & $28.6 \%$ & 90 & $18.3 \%$ & 0.057 \\
\hline Gravidity & & & & & 0.199 \\
\hline 1 & 21 & $25 \%$ & 168 & $35.1 \%$ & \\
\hline 2 & 36 & $41.7 \%$ & 175 & $36.6 \%$ & \\
\hline 3 & 22 & $26.2 \%$ & 92 & $19.2 \%$ & \\
\hline$>3$ & 6 & $7.1 \%$ & 43 & $9.0 \%$ & \\
\hline
\end{tabular}

Values are shown as mean \pm standard deviation, number (\%) 
Table 3. Univariate analysis of placental, intraoperative and postoperative characteristics $(\mathrm{n}=562)$

\begin{tabular}{|c|c|c|c|c|c|}
\hline & \multicolumn{2}{|c|}{ General anesthesia } & \multicolumn{2}{|c|}{ Regional anesthesia } & \multirow[t]{2}{*}{$\boldsymbol{P}$} \\
\hline & $\mathbf{n}$ & $\%$ & $\mathbf{n}$ & $\%$ & \\
\hline \multicolumn{5}{|l|}{ Types of placenta previa } & $<0.001$ \\
\hline Low lying & 10 & $11.9 \%$ & 141 & $29.5 \%$ & \\
\hline Marginal & 3 & $3.6 \%$ & 30 & $6.3 \%$ & \\
\hline Partialis & 3 & $3.6 \%$ & 41 & $8.6 \%$ & \\
\hline Totalis & 68 & $81 \%$ & 266 & $55.6 \%$ & \\
\hline \multicolumn{5}{|l|}{ Placental site } & 0.002 \\
\hline Posterior & 42 & $50 \%$ & 324 & $67.8 \%$ & \\
\hline Anterior & 34 & $40.5 \%$ & 136 & $28.5 \%$ & \\
\hline Anterior + posterior & 8 & $9.5 \%$ & 18 & $3.8 \%$ & \\
\hline \multicolumn{5}{|l|}{ Placental adherence } & 0.012 \\
\hline No & 75 & $89.3 \%$ & 460 & $96.2 \%$ & \\
\hline Accreta & 4 & $4.8 \%$ & 13 & $2.7 \%$ & \\
\hline Increata & 4 & $4.8 \%$ & 4 & $0.8 \%$ & \\
\hline Percreta & 1 & $1.2 \%$ & 1 & $0.2 \%$ & \\
\hline Cesarean hysterectomy & 19 & $22.6 \%$ & 27 & $5.6 \%$ & $<0.001$ \\
\hline \multicolumn{6}{|l|}{ Number of patients receiving } \\
\hline Blood transfusion & 52 & & 121 & & $<0.001$ \\
\hline Fresh frozen plasma & 15 & $17.9 \%$ & 17 & $3.6 \%$ & $<.0001$ \\
\hline Platelet & 5 & $6 \%$ & 2 & $0.4 \%$ & 0.001 \\
\hline Apgar score $<7$ at 1 min & 34 & $40.5 \%$ & 29 & $6.1 \%$ & $<0.001$ \\
\hline Apgar score $<7$ at 5 min & 15 & $11.3 \%$ & 8 & $1.7 \%$ & $<0.001$ \\
\hline \multicolumn{6}{|l|}{ Number of patients receiving } \\
\hline Methylergometrine & 11 & $131 \%$ & 96 & $20.1 \%$ & 0.176 \\
\hline Ephedrine & 14 & $16.7 \%$ & 317 & $66.3 \%$ & $<0.001$ \\
\hline Amount of ephedrine (mg) & 14 & $14.6 \pm 13.6$ & 317 & $15.8 \pm 10.1$ & 0.675 \\
\hline Estimated blood loss (mL) & 84 & $1610.7 \pm 1684.4$ & 478 & $1161.2 \pm 1104.2$ & 0.02 \\
\hline Duration of anesthesia (min) & 84 & $77.9 \pm 47.9$ & 479 & $60.7 \pm 26.8$ & 0.002 \\
\hline Intraoperative $\mathrm{SP} \leq 70 \mathrm{mmHg}$ & 3 & $3.6 \%$ & 19 & $4.0 \%$ & 1 \\
\hline Intraoperative HR < 45 bpm & 0 & $0 \%$ & 1 & $0.2 \%$ & 1 \\
\hline Intraoperative HR > 125 bpm & 7 & $8.3 \%$ & 5 & $1 \%$ & 1 \\
\hline Postoperative HCt\% & 84 & $30.3 \pm 5.4$ & 478 & $32.5 \pm 4.8$ & 0.001 \\
\hline Postop HCt $<30 \%$ & 38 & $40.9 \%$ & 88 & $18.8 \%$ & $<0.001$ \\
\hline
\end{tabular}

Values are shown as mean \pm standard deviation, number (\%); HR, heart rate; HCt, hematocrit.

When applying multivariate analysis, the factors associated with a choice of general anesthesia compared with regional anesthesia were identified; ASA physical status $(P<0.001)$, clinical presentation with bleeding ( $P=0.033$ ), anterior site of placenta $(P=0.025)$ receiving packed red cell transfusion $(P=<0.001)$, intraoperative heart rate higher than 125 beats per $\min (P=0.01)$ as shown in Table 4 .

Table 4. Factors related to general anesthesia for patient diagnosed with placenta previa undergoing cesarean delivery (multivariate analysis)

\begin{tabular}{|c|c|c|c|}
\hline Factors & \multicolumn{2}{|c|}{ Adjusted OR 95\% confident interval } & $\boldsymbol{P}$ \\
\hline \multicolumn{4}{|l|}{ American Society of } \\
\hline Anesthesiologists physical status & 2.7 & $1.7-4.3$ & $<0.001$ \\
\hline Bleeding presentation & 1.8 & $1.0-3.1$ & 0.033 \\
\hline Anterior site of placenta & 1.8 & $1.1-3.2$ & 0.025 \\
\hline Anterior + posterior site of placenta & 2.2 & $0.8-6.0$ & 0.102 \\
\hline Heart rate $>125$ bpm & 5.6 & $1.5-21.4$ & 0.011 \\
\hline Packed red cell transfusion & 3.4 & $2.0-5.7$ & $<0.001$ \\
\hline
\end{tabular}


There were no anesthetic problems (Tables 2 and 3) and no major anesthesia related complications. However, there was one case of maternal mortality, which was reported as part of a multicenter registry of patients receiving spinal anesthesia in Thailand [7]. The case was in a $33 \mathrm{y}$-old parturient, scheduled for elective cesarean delivery. The attending anesthesiologist performed an uneventful spinal anesthesia before prolonged hemorrhage necessitated hysterectomy. Induction of general anesthesia was performed during the hysterectomy. Maternal fatality occurred after massive hemorrhage with disseminated intravascular coagulopathy and a ruptured bladder [7]

\section{Discussion}

Recent widespread use of ultrasound has facilitated early diagnosis of placenta previa. The present study revealed the incidence of placenta previa of 11 per 1000 in our institution, this is higher than the incidence of 4.8 per 1000 in the United States [3]. This high incidence might be because of increasing referral of high risk patients to our hospital. There was no significant difference between patients receiving regional anesthesia or general anesthesia between the retrospective and prospective data collection periods. The majority of parturients (85.3\%) with diagnosis of placenta previa received regional anesthesia; particularly spinal anesthesia, while only $14.7 \%$ received general anesthesia. Another 13 (2.3\%) parturients received general anesthesia because of inadequate or failed spinal blockade. Therefore, the present study showed that regional anesthesia was the anesthetic technique of choice for $87.6 \%$ of parturients. Most anesthesiologists prefer providing regional anesthesia for cesarean delivery for placenta previa, whereas others prefer general anesthesia in all circumstances [4, 8, 9]. In a retrospective review of 147 cases of placenta previa, only a quarter of cases received regional anesthesia. There were no complications associated with the anesthetic technique [1]. Arcario et al. suggested that regional anesthesia is not contraindicated even in cases of simple placenta accreta [10]. Parekh et al. in a retrospective review also revealed that regional anesthesia was used in $60 \%$ of cases [5]. Combined spinal epidural anesthesia has also been suggested as anesthetic technique for placenta previa [11].

There were subgroups of 46 cases (8.2\%) of cesarean hysterectomy and 29 cases (5.2\%) of placenta adherence. Similar to other studies, the majority of hysterectomies were because of abnormal placentation and increased blood loss [12-15]. The present study found that attending anesthesiologists in our institution chose regional anesthesia for cesarean delivery in $58.7 \%$ of parturients with hysterectomy and $69.0 \%$ of parturients placental adherence. While the diagnosis of abnormal placentation cannot always be made by ultrasound, most placenta adherence in the present study was diagnosed intraoperatively. However, among 10 parturients set for possible cesarean hysterectomy, the attending anesthesiologists chose general anesthesia as main technique in 6 out of 10 cases. Moreover, 1 out of 4 patients received spinal anesthesia throughout with subsequent induction of general anesthesia. The reasons for choosing general anesthesia in elective cesarean hysterectomy is probably because of prolonged surgery, hemodynamic instability from massive blood loss, and patients discomfort. Chestnut and Redick reported 25 cases of using continuous epidural anesthesia for elective hysterectomy. While $28 \%$ of patients required intraoperative induction of general anesthesia [16].

In the univariate analysis, lower gestational age might be the explanation of significant lower body weight of parturients in the GA group. Moreover, there was a higher proportion of patients with a higher class of ASA physical status and emergency surgical status in the GA group. There were also several variables which were significantly different only in univariate analysis, but not in multivariate analysis, such as the types of placenta previa, presence of placental adherence, cesarean hysterectomy, number of patients receiving ephedrine, and number of newborns with an Apgar score $<7$ at 1 and $5 \mathrm{~min}$. Other factors significant only in the univariate analysis level were a higher postoperative hematocrit, lower estimated maternal blood loss, and less patients receiving packed red cell, fresh frozen, and platelet transfusion. A Cochrane systematic review of anesthesia for cesarean delivery showed that women who had neuraxial anesthesia were found to have a significantly lower difference between pre- and postoperative hematocrit, lower estimated blood loss, but have no significant difference in terms of neonatal Apgar score of $<6$ at 1 and 5 min [17].

In the multivariate analysis the significant variables were ASA physical status, clinical presentation of bleeding, anterior site of placenta, intraoperative heart rate $>125 \mathrm{bpm}$, and transfusion of packed red cells. The ASA physical status was a significant 
factor related to general anesthesia $(P<0.001)$. Anesthesiologists are 2.7 times more likely to choose general anesthesia when the ASA physical status of parturients are higher. Many studies suggest that general anesthesia is the preferable choice of anesthetic technique in high risk patients [18, 19]. Moreover, there might be a bias toward general anesthesia in patients with coexisting medical conditions [20, 21].

The present study demonstrated that general anesthesia was preferable with an adjusted odds ratio of 1.8 when the clinical presentation of patients was associated with bleeding. Anterior site of placenta related to a 1.8-fold increase in receiving general anesthesia. Oyelese and Smullian stated that orientation of placenta to the anterior uterine wall and patient status are factors that should be considered when choosing the anesthetic for parturients with placenta previa [22]. Patients in the GA group were more likely to have intraoperative heart rates $>125$ bpm (with an adjusted odds ratio of 5.6) and to receive packed red cell transfusion (with an adjusted odds ratio of 3.3). During light general anesthesia, the sympathetic reflex relates to tachycardia. In animal studies, regional anesthesia caused slower heart rates, greater stroke volume, higher arterial $\mathrm{pH}$, higher bicarbonate concentration, and lower catecholamine concentrations than general anesthesia [23]. The present study also showed an association between GA and higher frequency of blood transfusion. The possible explanations were selection bias for GA, which was frequently chosen for patients with an anterior placental site and presentation of bleeding. Hypotension was considered the most frequent side effect or complication related to regional anesthetic technique, particularly spinal anesthesia. However, hypotension can be controlled and did not lead to major adverse outcomes. There was no mortality and other serious complication related to the choice of anesthesia.

There are some limitations to the present study. First, this retrospective analysis was a nonrandomized, unblinded study that may be subject to some selection or observer bias. Second, there were some incomplete data because of the retrospective-cohort data collection. Third, the results of the present study represent only one tertiary referral center.

\section{Conclusion}

Most parturients in the present study received spinal anesthesia. Both neuraxial anesthesia and general anesthesia are safe anesthetic techniques for cesarean delivery in parturients diagnosed with placenta previa. General anesthesia correlated with intraoperative tachycardia (>125 bpm) and higher frequency of packed red cell transfusion. High ASA physical status, presentation of antepartum bleeding and anterior site of placenta are preanesthetic factors favoring general anesthesia in this group of patients.

\section{Acknowledgement}

The study was supported by the Chulalongkorn Research Centre for Quality, Safety and Innovation in Patient Care, King Chulalongkorn Memorial Hospital, Thai Red Cross Society. The authors have no conflicts of interest to report.

\section{References}

1. McShane PM, Heyl PS, Epstein MF. Maternal and perinatal morbidity resulting from placenta previa. Obstet Gynecol. 1985; 65:176-82.

2. Chestnut DH, Dewan DM, Redick LF, Caton D, Spielman FJ. Anesthetic management for obstetric hysterectomy: a multi-institutional study. Anesthesiology. 1989; 70:607-10.

3. Iyasu S, Saftlas AK, Rowley DL, Koonin LM, Lawson HW, Atrash HK. The epidemiology of placenta previa in the United States 1979 through 1987. Am J Obstet Gynecol. 1983; 168:1424-9.

4. Bonner SM, Haynes SR, Ryall D. The anaesthetic management of Caesarean section for placenta previa: a questionnaire survey. Anaesthesia. 1995; 50:992-4.

5. Parekh N, Husaini SWU, Russel IF. Caesarean section for placenta praevia: a retrospective study of anaesthetic management. Br J Anaesth. 2000; 84: 725-30.

6. Hong JY, Jee YS, Yoon HJ, Kim SM. Comparison of general and epidural anesthesia in elective cesarean section for placenta previa totalis: maternal hemodynamics, blood loss and neonatal outcome. Int J Obstet Anaesth. 2003; 12:12-6.

7. Charuluxananan $S$, Thienthong $S$, Rungreungvanich $\mathrm{M}$, Chanchayanon T, Chinachoti T, Kyokong O, Punjasawadwong Y. Cardiac arrest after spinal anesthesia in Thailand: a prospective multicenter registry of 40271 anesthetics. Anesth Analg. 2008; 107: 1735-41.

8. Peel WJ. A survey of the anaesthetic management of patients presenting for Caesarean section with high risk obstetric conditions. Int J Obstet Anaesth. 1996; 


\section{5:219-20}

9. Plumer MH, Rottman R. How anesthesiologists practice obstetric anesthesia. Responses of practicing obstetric anesthesiologists at the 1993 meeting of the Society for Obstetric Anesthesia and Perinatology. Reg Anesth. 1996; 21:49-60.

10. Arcario T, Greene M, Ostheimer GW, Datta S, Naulty JS. Risks of placenta previa/accreta in patients with previous Caesarean deliveries. Anesthesiology. 1988; 69 (Suppl 3A):A659.

11. Collis R, Garry M. CSE is the regional anaesthetic technique of choice for placenta praevia. Int J Obstet Anesth. 2001; 10:252-3.

12. Kwee A, Bots ML, Visser GH, Bruinse HW. Emergency perioperative hysterectomy: a prospective study in the Netherlands. Eur J Obstet Gynecol Reprod Biol. 2008; 124:187-92.

13. Muench MV, Baschat AA, Oyelese Y, Kush MI, Mighty HE, Malinow AM. Gravid hysterectomy: a decade of experience at an academic referral centre. J Reprod Med. 2008; 53:271-8.

14. Selo-Ojeme DO, Bhattacharjee P, Izuwa-Njoku NF, Kader RA. Emergency peripartum hysterectomy in a tertiary London Hospital. Arch Gynecol Obstet. 2005; 271:154-9.

15. Wright JD, Bonanno C, Shah M, Gaddipati S, Devine P. Peripartum Hysterectomy. Obstet Gynecol. 2010; 116:429-33.

16. Chestnut DH, Redick LF. Continuous epidural anesthesia for elective hysterectomy. South Med J.
1985; 78:1168-73.

17. Afolabi BB, Lesi FEA, Merah NA. Regional versus general anesthesia for caesarean section. Cochrane Database Sys Rev. 2006:CD004350

18. Sprung J, Warner ME, Contreras MG, Schroeder DR, Beighley CM, Wilson GA, Warner DO. Predictors of survival following cardiac arrest in patients undergoing noncardiac surgery: a study of 518,294 patients at a tertiary center. Anesthesiology. 2003; 99:259-69.

19. Aubas S, Biboulet P, Daures JP, du Cailar J. [Incidence and etiology of cardiac arrest occurring during the peroperative period and in the recovery room. Apropos of 102,468 anesthesia cases]. Ann Fr Anesth Reanim. 1991; 10:436-42. (article in French)

20. Braz LG, Modolo NSP, Nascimento JP, Bruschi BAM, Castiglia YMM, Ganem EM, de Carvalho LR, Braz JRC. Perioperative cardiac arrest: a study of 53718 anesthetics over a 9 yr from a Brazilian teaching hospital. Br J Anaesth. 2006; 96:569-75.

21. Kyokong O, Charuluxananan S, Werawatganon T, Termsombatborworn N, Leelachiewchankul F. Risk factors of perioperative death at a university hospital in Thailand: a registry of 50,409 anesthetics. Asian Biomed. 2008; 2:51-8.

22. Oyelese Y, Smullian J. Placenta previa, placenta accrete, and vasa previa. Obstet Gynecol. 2006; 107:927-41.

23. Shibata K, Yamamoto Y, Murakami S. Effects of epidural anesthesia on cardiovascular responses and survival in experimental hemorrhage shock in dogs. Anesthesiology. 1989; 71:953-9. 